\title{
Beyond EU navel-gazing: Taking stock of EU-centrism in the analysis of EU foreign policy
}

\author{
Floor Keuleers ${ }^{1}$, Daan Fonck ${ }^{1}$ and Stephan Keukeleire
}

\begin{abstract}
Concerns on the EU-centric character of EU foreign policy analysis have become more frequent in recent years, yet a systematic toolbox for diagnosing and remedying this problem is still lacking. This article's contribution is twofold. First, it proposes a new typology of three approaches to foreign policy analysis, giving conceptual body and nuance to the debate on EU-centrism. The typology can be used for scrutinizing existing analyses, as well as for shaping new research projects. The second part of the article applies this typology in a meta-analysis of post-Lisbon EU foreign policy scholarship. To this end, it analyses a built-for-purpose dataset of 451 articles, which covers all work on EU foreign policy published in 2010-2014 in seven key journals. It finds that academic work on EU foreign policy is indeed rife with EU-centric research questions. Moreover, this is the case irrespective of the policy area under study and of the focus of the journal.
\end{abstract}

\section{Key words}

Foreign policy, European Union, EU-centrism, policy cycle, meta-analysis

\section{Introduction}

Over the last years, an increasing number of academics have come to point out the 'excessively Eurocentric perspective' of existing research on European Union (EU) foreign policy, which is seen to undermine the relevance of scholarship on this topic (Lucarelli, 2014: 11; Adriaensen et al., 2013; Mayer and Zielonka, 2012; Mayer, 2008; Keukeleire, 2014). Discontent with this (perceived) state of affairs has led some to call for 'a paradigm shift that decentres the study and practice of Europe's international relations' (Fisher Onar and Nicolaïdis, 2013: 283). It has also inspired the development of new sets of literature seeking to provide an alternative, of which the EU external perceptions literature might be the most established example (Chaban and Holland, 2008; Chaban and Holland, 2014; Lucarelli and Fioramonti, 2010; Elgström, 2007). The underlying premise of EU-centrism, however, remains both conceptually vague and unsubstantiated empirically. What exactly constitutes an EU-centric approach to the study of EU foreign policy? Is such an approach problematic and, if so, why? What might an alternative look like? And is it true that the existing literature is characterised by a dominance of EU-centric work?

The objective of this article is dual. First, it elucidates the concept of EU-centrism, by building upon the basic framework of the policy cycle and introducing a threefold typology of approaches to the study of EU foreign policy. The three types or approaches -inward-oriented, inside-out, and outsidein- are delineated in terms of their main aims, key research questions and dominant concepts. Going 
beyond the crude distinction between 'EU-centric' and 'non-EU-centric', this typology aims to offer a more systematic and fine-grained conceptual tool. The second objective of the article is to provide a thorough mapping of existing research on EU foreign policy, to scrutinise whether there is indeed a problematic dominance of EU-centric work. To this effect, it analyses an original, built-for-purpose dataset containing all articles on EU foreign policy published in the post-Lisbon period (2010-2014) by seven prominent journals with an explicit EU focus. The total number of articles analysed is 451 .

The article is structured as follows. First, the basic heuristic device of the policy cycle is used to clarify what is meant by the term EU-centrism. The second section presents the conceptual framework, discussing in-depth the core tenets of each of the three approaches to analysing EU foreign policy. Section three starts by explaining the construction of the dataset and the methodological choices regarding the empirical analysis. It then goes on to present the results and insights from the mapping exercise, establishing that the literature is indeed highly skewed in favour of a limited subset of approaches and research questions.

\section{(EU) foreign policy analysis and the policy cycle}

When academics express concern about EU-centrism in the analysis of EU foreign policy, what do they actually mean by this? While references to the issue are often fleeting, one of the more substantive discussions can be found with Hartmut Mayer. Mayer has argued that 'most scholarship and policy discourse about the future of European foreign policy remains too self-absorbed, looking at Europe through European eyes in a well-shaped European mirror'. He further explains that 'research on EU foreign policy has been, on the whole, a bit too narrow and specialized', focusing excessively on topics such as institutional questions, EU-member state relations in foreign policy, the uniqueness of the EU as an international actor, or the EU as a model. According to Mayer, however, 'not Europe, but global concerns, should be the benchmark for the EU in external affairs' (Mayer, 2008: 8-11).

In a similar vein, Sonia Lucarelli has argued that the literature on the EU is characterised by 'strong Eurocentrism', in the sense that it pays very little attention to non-Europeans' perceptions, interests and world-views. As a result, she says, the EU's self-representation and academic representation as a 'power for the good' 'has been largely assumed not only to be a reality, but also to be recognised by external Others'. This image is rarely 'challenged by studies on the actual degree of external recognition of this distinctive characteristic' (Lucarelli, 2014: 1-2).

These arguments deserve some further scrutiny. In particular, one might question whether 'non EUcentric' assessment of the kind Mayer and Lucarelli plead for is in fact a task for EU foreign policy analysts. Do the contours of foreign policy analysis as a field of study not make it natural -and even desirable- for its scholars to be preoccupied mainly with how the EU arrives at foreign policy decisions and initiatives? The uniquely hybrid character of the EU as an international actor, as well as the changes to its foreign policy architecture in recent years, appear to lend further importance to such a research focus.

It is argued here, however, that it is not satisfactory to dismiss EU-centric analysis as a natural corollary of the need to maintain a clear focus within the field of EU foreign policy analysis. To further explain this point, it is useful to start by taking a step back from the specificities of EU foreign policy analysis and even of foreign policy analysis more generally, and to recognise what they are in essence, i.e. a particular type of public policy analysis. This implies that basic heuristic devices from 
public policy analysis may also shed new light on the analysis of (EU) foreign policy, an argument that has indeed been made before by others (Ingram and Fiederlein, 1988; Lentner, 2006; Sanchez et al., 2006). Concretely, a very basic framework stemming from public policy analysis, that of the policy cycle, serves as a useful point of departure in elucidating why EU-centrism is limiting and hence problematic for EU foreign policy analysis as a discipline.

Despite a plethora of operationalisations, the policy cycle or policy stages model is in essence based upon the premise that policy processes can be analysed in terms of a set of distinct stages. Each stage involves different actors or institutions with their own specific dynamics, procedures and issues, justifying its designation as a specific category for analysis (Howlett et al., 2009; Hill, 2013; Jann and Wegrich, 2007). For the purpose of this article, the policy cycle phases can be understood as consisting of three broad categories: the processes leading up to and including the decision-making, the actual implementation of policies, and the eventual evaluation of policies. Following Howlett et al. (2009), the first category ranges from the identification of problems to the moment a response is formulated. It involves information-gathering, problem identification and agenda-setting, followed by policy formulation with specific policy instruments based on a policy design, and resulting in an actual decision-making process. Once decisions have been taken, the implementation phase takes effect, involving the operationalisation of policy goals and the concrete means to attain them. This stage is concerned with the allocation of instruments and resources, as well as issues of efficiency or effectiveness. Finally, in the policy evaluation phase, the focus is on policy impacts (the reaction of the affected target group) and outcomes (the wider effects of the policy within the respective social sector) (Jann and Wegrich, 2007: 44).

The difference between policy implementation and evaluation deserves some further explanation, especially in light of the typology introduced in the next section. While analyses of implementation and those of impacts and outcomes are both concerned with certain aspects of policy success, the latter are more encompassing in scope. First, evaluation should take into account different types of outcomes. These include null effects (no impact at all on the target areas), perverse effects (which run counter to the stated goals), and side-effects (which can be detrimental or beneficial) (Vedung, 1997: 49-55). Second, and more importantly, the criteria of merit against which policies are evaluated do not have to be limited to avowed intervention goals (i.e. the stated goals of a programme). Evaluation can also, for instance, take as its point of departure 'the concerns and expectations of the clients or of other stakeholding audiences', or even 'yardsticks drawn from political philosophy' (Vedung, 1997: 10). This second point will prove especially relevant for the analysis of foreign policy, where the yardsticks on which decision-making is based can be very different from assessments by local stakeholding audiences abroad. This insight is also clearly reflected in the typology presented in the next section.

Having explained its basic thrusts, it should be acknowledged that the policy cycle framework is a contested one, which has rightfully been critiqued for presenting an overly simplistic and sterile version of the policy process. The extent to which this is problematic, however, depends on the purpose for which the framework is being used (Bridgman and Davis, 2003). It is recognised here that the policy cycle is not a perfect representation of how policies come about in real life (John, 1998: 2237; Sabatier and Jenkins-Smith, 1993; Howlett et al., 2009), nor is it necessarily a normative ideal that policy-makers should aspire to (on this topic, see for example Howard, 2005; Althaus et al., 2012; Smith and May, 1980). As an analytical tool, the policy cycle is moreover limited by its descriptive character and lack of explanatory power, which means it can never be the sole conceptual underpinning for a research project (Sabatier, 1992). What most scholars appear to agree upon, however, is the policy cycle's value as a heuristic device, as it 'fulfils a vital role in structuring the 
vast amount of literature, the abundance of theoretical concepts, analytical tools and empirical studies' (Jann and Wegrich, 2007: 57; Givoni et al., 2012; Hill, 2013; Versluis et al., 2011). Concretely, the policy cycle captures 'how, in thinking about the policy process, one's attention is drawn to beginnings, middles, and endings that may lead to new beginnings' (May and Wildavsky, 1978: 1213). It is in this sense that the policy cycle framework is used in this article, i.e. as a structuring device. The central insight is that 'depending on the stage of the policy cycle under examination, researchers ask different questions' (May and Wildavsky, 1978: 10; Jann and Wegrich, 2007: 58), with 'different research methods' (Bridgman and Davis, 2003: 99), and where 'hypotheses may be developed and tested that apply only to those parts' (Hill, 2014: 6-7).

Starting from this insight, one possible way of understanding EU-centrism in EU foreign policy analysis is in terms of a very dominant focus on certain stages of the policy cycle as elaborated above (and on the associated research questions), which goes hand in hand with a relative neglect of other possible questions. Specifically, a vast amount of work appears to be done on agenda-setting, policy formulation and decision-making within EU foreign policy. Research on implementation seems much less abundant, but a dearth of work is particularly apparent regarding the impact and outcomes of EU foreign policies. Given that the study of impacts and outcomes is considered an integral part of public policy analysis, such a lopsided focus is problematic, as it severely limits the analytical and policyoriented contribution this literature can make.

The preceding paragraphs formed a first step in presenting how this article conceptualises EU-centrism in EU foreign policy analysis. ${ }^{2}$ To be able to systematically map existing and future research, however, a more fine-grained tool is needed. The following section therefore further develops the idea that different policy stages lead to different research questions, resulting in a novel threefold typology of approaches to EU foreign policy analysis. In doing so, it brings back in some of the complexities and idiosyncrasies of EU foreign policy as a field of study.

\section{A typology of approaches to the study of EU foreign policy}

The aim of the typology presented in this section is twofold. On the one hand, it allows for a systematic mapping of existing literature, which facilitates a more precise analysis of whether and where EU-centrism is present in the analysis of EU foreign policy. On the other hand, this typology can be seen as a tool for designing and focusing future research, as it points towards the wide range of research questions that can be asked for a particular policy area or region. In the latter sense, it builds upon existing work that underlines the impact of conceptual lenses on 'what is observed and how it is observed' in analysing (European) foreign policy (Jørgensen, 2004: 35). In essence, therefore, this section seeks to offer a systematic yet practical and ready-to-use tool, complementary to more theoretical takes on the topic of EU-centrism.

Our typology starts from the widely varying focus of existing analyses of EU foreign policy. At one extreme, there are studies focused purely on institutional dynamics within the EU itself. At the other extreme, there is research that is very close to area studies, in that it mainly studies the partner country or region of the EU. The typology presented here further categorises the space in between these two extremes, corresponding to the three broad stages of the policy cycle model. It does so by differentiating between three approaches to the study of EU foreign policy: inward-oriented, insideout, and outside-in ${ }^{3}$. The following paragraphs characterise each approach and provide an overview of the research questions that are at its core. 
The first approach in our typology, the inward-oriented approach, mirrors the first stage of the policy cycle as described above. This strand of research is fully centred upon the actor projecting its foreign policy onto the outside world, focusing on agenda setting, policy formulation, and decision making. Translating these general concepts to the specific field of EU foreign policy analysis, the following core research questions of this approach can be identified. How are foreign policy decisions in field $X$ made? What is the role and influence of institution $Y$ or member state $Z$ within this decision-making process, and how can this be explained? Why was policy instrument $X$ opted for in tackling a particular situation? Is there coherence between various parts of the EU's foreign policy, and how can this coherence be improved? What do the developments in foreign policy field Y tell us about the dynamics of EU integration?

The second approach in our typology, the inside-out approach, is closely related to the implementation phase of the policy cycle. It looks beyond decision-making to assess the actual content and results of a particular policy, but does so purely from the point of view of the foreign policy actor and the implementation objectives it has set. Core questions from the specific field of EU foreign policy analysis that belong in this approach are the following ones: What are the EU's goals in foreign policy field X? To what extent has it been able to attain these goals? Is the EU presenting itself as a norm setter in field Y? Which features of the EU can explain its influence or lack thereof? Does policy instrument $X$ contribute to attaining goal $Y$ ? To what extent does the EU possess actorness in field $Z$, and which factors determine this?

The third approach, the outside-in approach, entails that a foreign policy is examined from the perspective of the country or region that it is targeted at. In terms of the policy cycle, this is where questions regarding impacts, outcomes and stakeholder evaluations are asked. Compared to an insideout perspective, the question is now not so much whether the measures envisioned by the EU were implemented, but what the consequences and relevance of this are in the context of the target country or region. Applied to the field of EU foreign policy analysis, core questions of this approach include: What are the consequences of the EU's policy for the elites or population within the country? What is the relevance and impact of the EU's policy regarding the challenges facing the country? What is the domestic context within which EU policies interfere or within which negotiations with the EU take place? How does this context affect the implementation and outcomes of EU policies? What is the perception or legitimacy of the EU in the eyes of various domestic groups, and do they support EUpromoted reforms? How do audiences within the country understand relevant concepts (e.g. sovereignty, human rights, legitimacy) ${ }^{4}$

To further clarify the distinctive perspective of each of the three approaches, it is useful to look at some examples of how they play out in real-life research projects included in our database. For the sake of comparison, the following examples all relate to the same specific case, namely EU foreign policy towards Turkey. Turkey was chosen for this purpose because of the number and variation of articles on this topic in the database. First, a clear example of an inward-oriented approach can be found in the research of Bürgin (2013). He analyses how a combination of the Commission's argumentative strength on the one hand, and the coalition between the Commission and the Danish Council Presidency on the other, led the EU to open a visa liberalisation with Turkey. Bürgin's article hence looks at the internal origin of a particular policy, and at the role of different EU institutions and member states therein, resembling the stages of problem definition, agenda-setting and decisionmaking of the policy cycle. Research by Ugur (2010), then, demonstrates an application of an insideout approach. His article details how the EU's accession negotiations were suboptimal from the EU's 
point of view. Focusing on the design of the policy (i.e. the open-ended character of the accession negotiations), the author explains inadequate convergence reforms in Turkey. In other words, Ugur analyses problems of policy design and (ineffective) implementation. Finally, an example of an outside-in approach to EU's foreign policy towards Turkey can be found in Ergun's work (2010), which makes an evaluation of the EU's transformative power over Turkey's civil society. Her account starts with an in-depth analysis of Turkish civil society development, and then situates the engagement of the EU within this specific domestic context. Particular attention is paid to how Turkish civil society representatives have perceived the contribution of European actors to ongoing processes of socio-political transformation in Turkey, especially the consolidation of democracy.

The three approaches described above are not mutually exclusive. Rather, they should be understood as categories that feed into one another, as depicted in Figure 1. At the beginning of the cycle is the inward-oriented approach, given that most research on EU foreign policy dedicates at least some attention to internal power dynamics, institutional relations, and how these play out in terms of agenda setting and decision making. A subset of research goes beyond this to include an inside-out focus, looking at EU foreign policy goals and goal attainment in the sense of successful implementation. An even broader scope is obtained in an outside-in approach, where the study of the EU's policy is embedded in a thorough analysis of the local context it is targeted at. This cumulative relationship between the three approaches entails that an article employing an outside-in approach will often also devote some attention to inward-oriented and inside-out research questions. This is reflected in the trigger-coding strategy used in the construction of the dataset, which will be explained in more detail in the following section.

Figure 1. The spectrum of (European) foreign policy analysis.

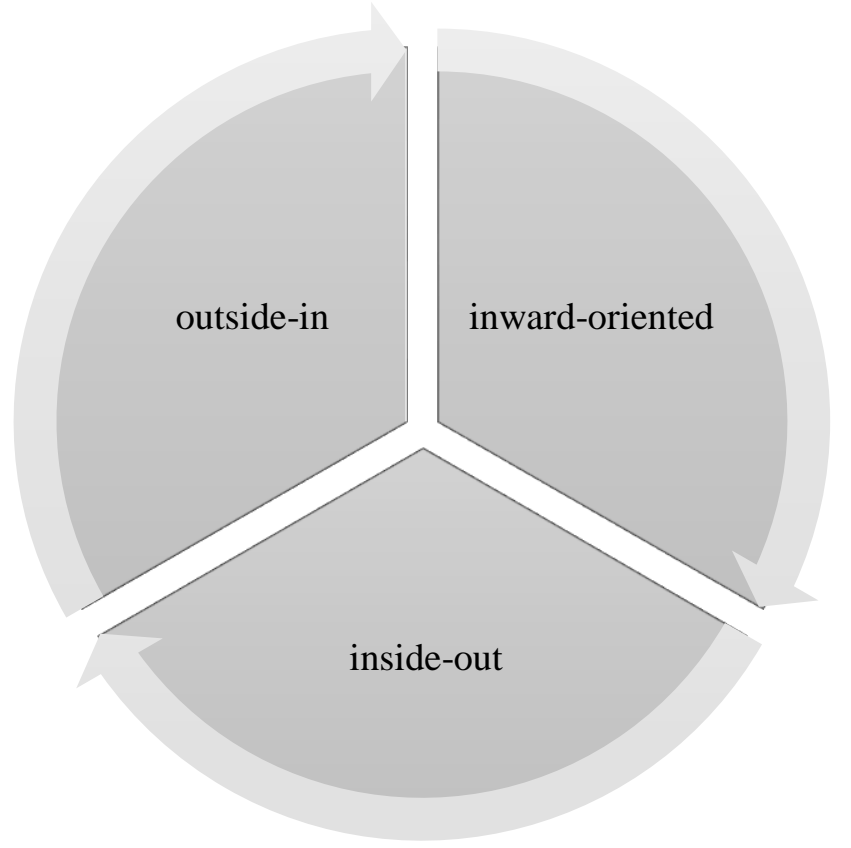




\section{EU-centrism in EU foreign policy analysis: a mapping exercise}

\section{Methodology}

The empirical component of this article provides a mapping of contemporary scholarship on EU foreign policy, on the basis of the typology presented in the previous section. It is to be situated in what Jensen and Kristensen have recently termed the 'quantitative meta-EU literature' (2013: 2). While still limited at present, this strand of literature is steadily gaining traction, with several prominent examples providing useful methodological foundations for this paper to build upon (Exadaktylos and Radaelli, 2009; Jupille, 2006; Jensen and Kristensen, 2013; Franchino, 2005; Keeler, 2005; Bunea and Baumgartner, 2014). The core of the quantitative meta-EU literature is 'to take articles as units, code the properties of the units via a protocol (so that a quantitative treatment becomes possible) and then analyse the data' $[\ldots]$ 'to investigate and describe the pattern of findings' (Exadaktylos and Radaelli, 2009: 509). In the context of this article, such an approach allows for considering each article in some depth before categorising it, while at the same time making it possible to systematically analyse and visually present a large volume of data.

The contours of the dataset are based upon two important choices. To begin with, it was decided to cover the five-year period 2010-2014. This decision reflects both our interest in contemporary scholarship as well as the need to keep the data volume manageable. The entry into force of the Lisbon Treaty was chosen as the starting point, given its profound impact upon the functioning of EU foreign policy. A comparison of pre- and post-Lisbon scholarship would also have been very interesting, as institutional innovations can be expected to result in an increase in EU-centric analysis. However, the very time-intensive manual coding process meant that such a large scope was not feasible. Subsequently, publications needed to be selected for inclusion in the dataset. Following Bunea and Baumgartner (2014), a focus on journals only was deemed preferable. The justification for this choice is threefold. First, given the labour intensity of the coding by hand, this approach kept the scope of the dataset manageable and clearly delineated. Second, it can be argued that journal publications have a broader outreach and are hence more influential in knowledge accumulation than other types of publications (books, conference papers, dissertations). Third, there is considerable overlap between the authors represented in journals and in books, as research projects leading to influential books usually also result in journal publications.

Rosamond's overview of 'journals that self-identify as outlets for the discussion of EU politics/European integration' served as the starting point for the selection of journals (Rosamond, 2007: 11). This resulted in the inclusion of the Journal of Common Market Studies, Journal of European Public Policy, Journal of European Integration, European Integration Online Papers, and European Foreign Affairs Review. The sixth journal on Rosamond's list, European Union Politics, was excluded after having established the very low number of articles focusing on EU foreign policy. Similar observations informed the decision not to select West European Politics, European Journal of International Relations, and International Organization, three other journals that were not mentioned by Rosamond but have been included in other meta-analyses of EU literature (Jensen and Kristensen, 2013; Jupille, 2006). Conversely, European Security and Cooperation and Conflict were added to the selection. The primary focus of these two journals is thematic rather than regional, but both their mission statements ${ }^{5}$ and their actual content (see Table 1) indicate that this is combined with a strong European and EU focus. The decision to include these two journals was inspired by Keeler's argument on the relevance of a broader set of journals for scholarship on the EU, which holds particular sway when assessing work on (alternative approaches to) EU foreign policy (Keeler, 2005). As is clear from 
the overview in Table 1, the resulting list of journals is varied in terms of editorial base, ISI accreditation, and the extent to which the EU's and/or its international role form the main focus.

Table 1. Overview of journals included in the dataset.

\begin{tabular}{|c|c|c|c|c|c|c|}
\hline Journal & Founded $^{\mathrm{a}}$ & $\begin{array}{l}\text { Current editorial } \\
\text { base }^{\mathrm{a}}\end{array}$ & $\begin{array}{l}\text { ISI } \\
\text { status }^{b}\end{array}$ & $\begin{array}{r}\text { Content on } \\
\text { EU foreign } \\
\text { policy }^{c}\end{array}$ & $\begin{array}{r}\text { Articles } \\
\text { in } \\
\text { dataset }^{c}\end{array}$ & $\begin{array}{r}\text { Proportion } \\
\text { in dataset }^{\mathrm{c}}\end{array}$ \\
\hline $\begin{array}{l}\text { Journal of Common Market } \\
\text { Studies (JCMS) }\end{array}$ & 1962 & UK & Yes & $21.3 \%$ & 68 & $15.1 \%$ \\
\hline $\begin{array}{l}\text { Journal of European } \\
\text { Policy (JEPP) }\end{array}$ & 1994 & UK & Yes & $17.6 \%$ & 64 & $14.2 \%$ \\
\hline $\begin{array}{l}\text { Journal of European Integration } \\
\text { (JEI) }\end{array}$ & 1977 & Netherlands & $\mathrm{No}^{\mathrm{d}}$ & $28.4 \%$ & 57 & $12.6 \%$ \\
\hline $\begin{array}{ll}\text { European Integration } & \text { Online } \\
\text { Papers (EIOP) } & \\
\end{array}$ & 1998 & Austria & Yes & $40.0 \%$ & 22 & $4.9 \%$ \\
\hline $\begin{array}{l}\text { European Foreign Affairs Review } \\
\text { (EFAR) }\end{array}$ & 1996 & $\begin{array}{l}\text { Belgium/Canada/ } \\
\text { Netherlands }\end{array}$ & No & $79.0 \%$ & 143 & $31.7 \%$ \\
\hline European Security (ES) & 1992 & UK & No & $43.2 \%$ & 64 & $14.2 \%$ \\
\hline Cooperation and Conflict (CC) & 1965 & Sweden & Yes & $26.8 \%$ & 33 & $7.3 \%$ \\
\hline \multicolumn{7}{|c|}{$\begin{array}{l}\text { a Source: journal websites. } \\
\text { b Source: Journal Citation Reports on ISI Web of Science website } \\
\text { c Source: authors' own calculations } \\
\text { d Source: Journal of European Integration has recently been accepted into the Thomson Reuter Social Science Citation Index; } \\
\text { its first impact factor is due in } 2015 .\end{array}$} \\
\hline
\end{tabular}

For these seven journals and the time period under consideration (2010-2014), all regular original articles dealing with EU foreign policy were entered into the dataset. The selection of articles was based upon Hill's broad definition of foreign policy as 'the sum of official external relations' (Hill, 2003: 3). For the specific case of the EU, this implies that not only articles on the Common Foreign and Security Policy (CFSP) and the Common Security and Defense Policy (CSDP) were included, but also work on trade, development, enlargement and external environmental policy (Keukeleire and Delreux, 2014: 1). To be included, articles needed to be analytical and EU-focused in nature. This entails that articles presenting a general and descriptive overview of the EU's relations with a particular partner, without a clear underlying research question, were excluded from the database. Similarly, articles focusing exclusively on dynamics within the EU's partner countries, with no or very marginal attention to the EU itself, were not taken on board. Finally, texts other than regular articles, such as editorials, book reviews and review essays, introductions to special issues, annual reviews, and policy or research agendas were not included. The total number of articles covered by the dataset is 451 , dispersed quite evenly over the five years.

For each of the articles, the following properties were coded: journal, year, approach, region, policy area, and residence of author ${ }^{6}$. The coding process was carried out by two researchers. At the start of the process, a test phase was held in which both researchers coded the same subset of the articles, in order to check and increase inter-coder reliability. The rest of the material was divided among the two coders; ambiguous cases were jointly discussed and settled by consensus. A coding list of regions and policy areas was obtained inductively in a first round of coding, to follow as closely as possible the relevant distinctions found in the material itself. The approach of each article was coded using the threefold typology presented above. 
In coding the approach of each article, the coders took into account the whole text of the article. The coding decision was not based upon the mere presence of certain concepts, as a single term can be conceptualised and applied in very different ways. ${ }^{7}$ Instead, it was based upon the central research question(s) underlying each article. These research questions were sometimes explicitly formulated by the author, but more often remained implicit. Where applicable, the data collection method of the author was also taken into account, with interviews carried out in and documents collected from the target country considered an indication of an outside-in perspective.

While authors often combine several approaches within one article, only one approach could be linked to each article in the dataset. This difficulty was resolved by using the 'trigger coding strategy' described by Jupille in his meta-analysis of methodology in European Studies (2006: 223-224). In the present article, a trigger coding strategy entails that each article is by default coded as inward-looking, until a substantive focus in the article on, for instance, the effectiveness of international action triggers coding as inside-out. Similarly, an inside-out coding changes to an outside-in coding when substantive attention is paid to the local context of EU foreign policy, its impact or legitimacy. The hierarchy of approaches that is implicit in this strategy reflects the fact that while almost all work on EU foreign policy devotes some space to the institutional underpinnings and origins of certain policies, only some articles supplement this with an assessment of EU effectiveness in implementation, and even fewer look at the actual impact or reception on the ground. This implicit hierarchy follows from the cumulative relationship between the three approaches that was discussed in the previous section.

\section{Results}

The key question in this empirical section is whether EU-centric approaches (in the sense discussed in the previous section) do indeed pervade current scholarship on EU foreign policy, a concern that has repeatedly been expressed over the last years. Figure 2, which presents the general distribution of approaches within the entire dataset, shows that this indeed appears to be the case. No less than 81.59 per cent of articles look at the EU's foreign policy from an inward-oriented or inside-out perspective, meaning that they only focus on decision-making (and the various processes leading up to it) or implementation. Only 18.40 per cent of articles, i.e. one out of every 5.5 analyses of EU foreign policy, pay attention to the actual impact, relevance or evaluation of the EU's policy in the targeted state or region. 
Figure 2. Occurrence of the five approaches in seven selected journals (2010-2014).

Approach

口inward

Zlnside-out

Goutside-in

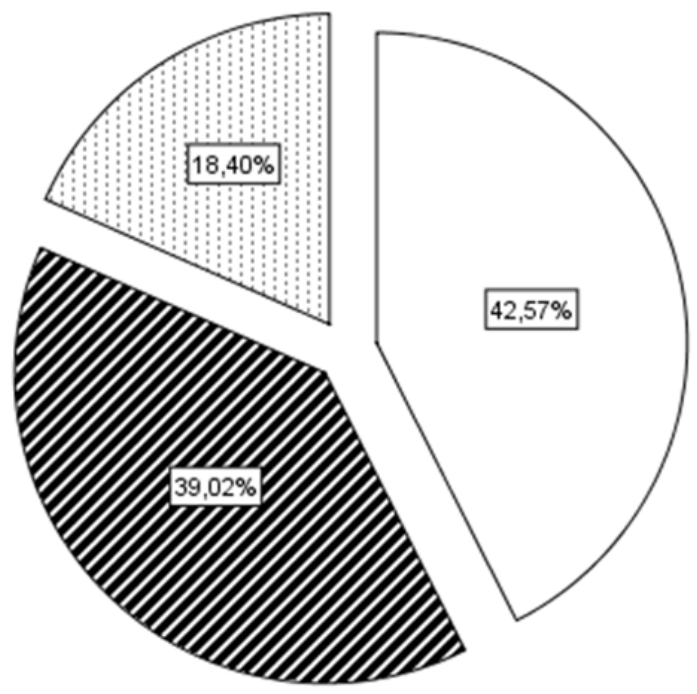


Figure 3 shows the presence of the different approaches throughout the five years under study. It indicates that the large share of inward-oriented and inside-out approaches is fairly stable over time.

Figure 3. Occurrence of the five approaches throughout time.

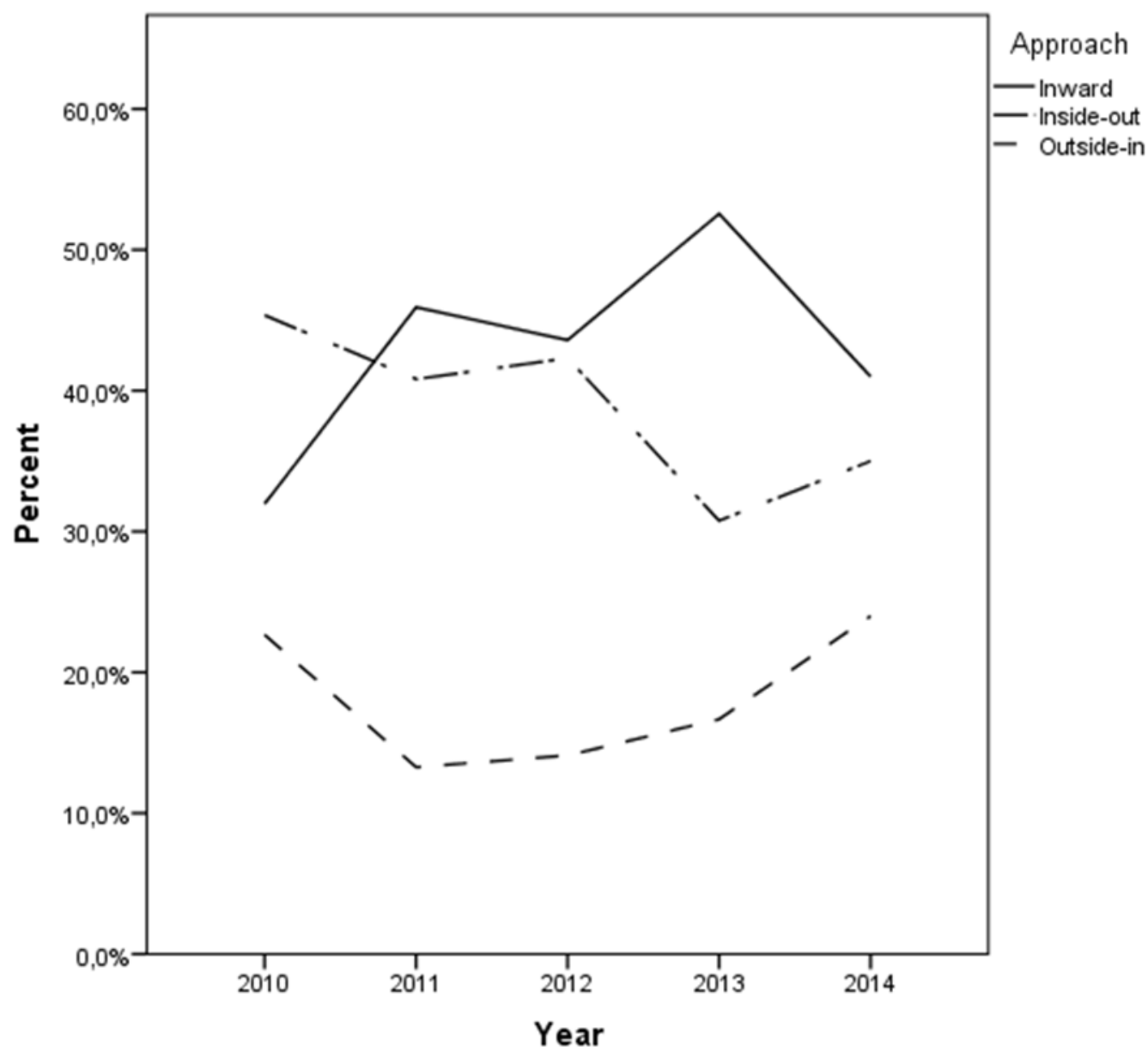

Such an overrepresentation of EU-centric approaches in the entire dataset may, however, be masking a more nuanced underlying picture. This is related to the variety of foreign policy domains and journals included in the dataset, not all of which may be equally conducive to an outside-in approach. It is hence useful to deconstruct the general picture a bit more along these lines.

First, it seems intuitively clear that an outside-in approach is more crucial in some areas of foreign policy than in others. It could be argued that the need for an outside-in approach co-varies with two characteristics of a foreign policy area. ${ }^{8}$ On the one hand, outside-in approaches are more important for established areas of EU foreign policy, where the EU has clear competences and substantial resources. In policy areas that are only starting to be tackled by the EU, it is to be expected that major academic attention will be devoted to the internal workings and integration dynamics of the EU. On the other hand, outside-in approaches are particularly indispensable when the EU's primary goal is to sustainably build or change structures in a partner country. In such policy areas, an in-depth assessment of the EU's policy and its impacts and outcomes is only possible when taking into account the partner country context (Keukeleire and Delreux, 2014: 28-31). In areas where the EU is more directly pursuing its own strategic or economic interests, the added value of an outside-in approach 
might be more moderate. It does, however, have relevance in those cases as well, as it can shed light on the sensitivities and domestic context of the EU's counterparts in international interactions, which shape the EU's room for maneuver.

Combining these two dimensions, it is possible to indicate the policy areas for which outside-in approaches are the most relevant. Figure 4 applies this reasoning to the dataset, by presenting the results for a subset of articles. The articles in this subset cover foreign policy areas in which the EU has clear competences and significant resources, and where its goal is primarily to sustainably alter structures within the partner countries and regions. Specifically, it includes the 177 articles dealing with the following policy domains: enlargement, external governance and policy diffusion, democracy promotion, CSDP missions ${ }^{9}$, conflict management and peace building, development policy, the development-trade nexus, and the development-security nexus.

As shown by Figure 4, the high relevance of outside-in approaches for these issue areas is not reflected in the existing literature. Inward-oriented and inside-out approaches still make up 76.27 per cent of the articles in the subset. While this is a slight decrease compared to the dataset as a whole, it means that more than three quarters of the articles in question still refrain from assessing the outcomes and impacts of the EU policy under study, focusing rather on the institutional environment within which policies come about or on the realisation of EU programme goals. EU-centric research questions therefore appear to be a pervasive feature of the literature, rather than a phenomenon that reflects the specificities of different policy areas.

Figure 4. Occurrence of the five approaches in articles on selected policy domains.

Approach

口inward

Znside-out

Goutside-in

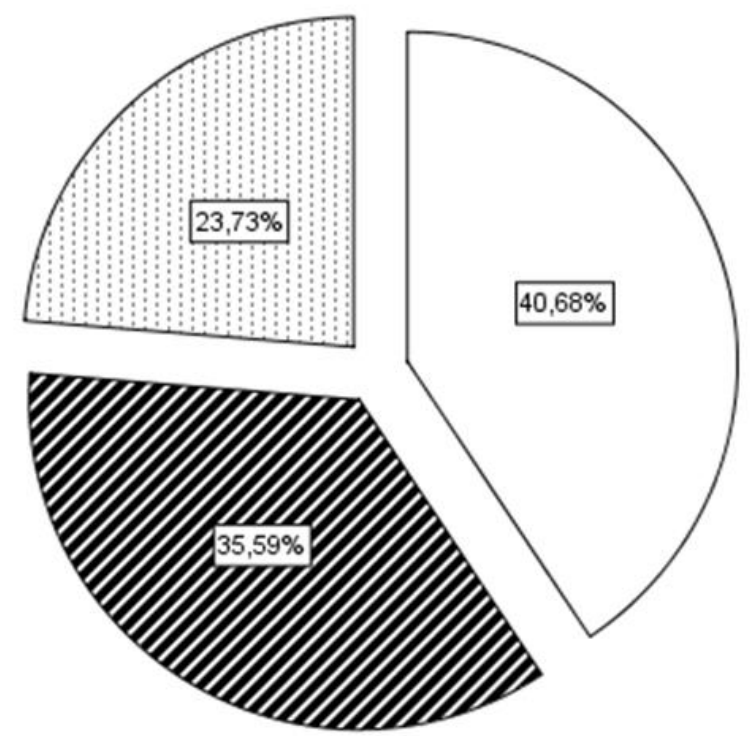


A second possible explanation for the large number of articles in the dataset focusing on EU-centric research questions, is the fact that it combines articles from very different journals. While all of the included journals publish work on EU foreign policy, each has its own (sub-)disciplinary background and scope. Some have an explicitly inward-oriented scope, which may distort the overall numbers. Table 2 therefore presents a breakdown of the approaches present in each of the journals.

Table 2. Occurrence of the three approaches in the different journals (per cent).

\begin{tabular}{|c|c|c|c|}
\hline Journal & Inward & Inside-out & Outside-in \\
\hline Journal of Common Market Studies (JCMS) & 47.1 & 35.3 & 17.6 \\
\hline Journal of European Public Policy (JEPP) & 42.2 & 54.7 & 3.1 \\
\hline Journal of European Integration (JEI) & 35.1 & 40.4 & 24.6 \\
\hline European Integration Online Papers (EIOP) & 77.3 & 18.2 & 4.5 \\
\hline European Foreign Affairs Review (EFAR) & 35.7 & 39.2 & 25.2 \\
\hline European Security (ES) & 37.5 & 42.2 & 20.3 \\
\hline Cooperation and Conflict (CC) & 63.6 & 21.2 & 15.2 \\
\hline
\end{tabular}

In line with expectations, Table 2 shows that journals focusing primarily on the dynamics of European integration, such as Journal of European Public Policy and European Integration online Papers, indeed have a very large share publications focusing on inward-oriented and inside-out research questions. What is remarkable, however, is the rather similar focus of journals who are claiming to offer an alternative point of view. European Security, for instance, explicitly presents itself as 'interested in non-European perspectives on Europe in a global context' (European Security, 2014). Yet over the last five years, only one out of every five articles in this journal employed an outside-in perspective. More generally, Table 2 shows that there is relatively little variation between journals, with inward-oriented and inside-out approaches constituting at least three quarters of articles on the EU's foreign policies in every journal analysed. It appears that the presence of EU-centrism does not merely mirror the traditional 'division of labour' between the different journals. Indeed, readers interested in context-aware and critical analyses of EU relations with specific countries and regions may be hard put to find a journal catering to their needs.

While policy areas and journals vary less in terms of approaches than might be expected, Figure 5 points to one characteristic of articles that does appear to have a strong relationship with the approach that is adopted. It distinguishes between two sets of articles: those by authors working in the EU or North America, and those of which at least one author resides in another part of the world. Two observations can be made. First, as shown by the pie chart in the upper left corner, a very large majority of the articles in the dataset (91.35 per cent) are by authors residing in Europe or NorthAmerica. Second, as shown by the bar chart, work from researchers residing outside Europe and North-America (or co-authored with such researchers) is less EU-centric and clearly favours outside-in approaches. This may be related to the greater familiarity these authors have with particular receiving areas of EU foreign policy, which can lead them to ask more outside-in research questions as well as equip them with the skills and data access to answer these question empirically. It can be concluded, therefore, that while journals rely heavily on western authors for analyses of EU foreign policy, nonwestern authors could contribute towards diversifying the analysis of EU foreign policy. 
Figure 5. Articles by residence of authors (a) and approaches according to residence (b)*.

a)

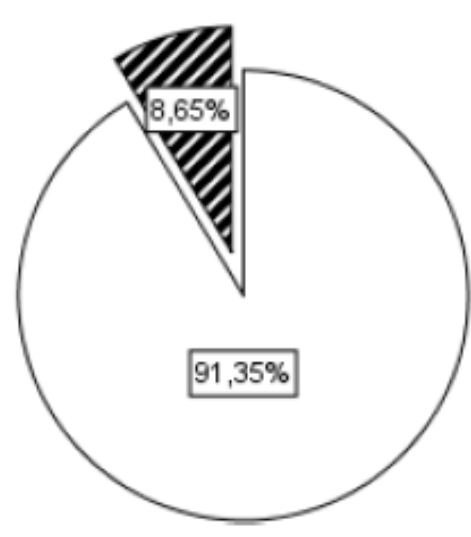

b)

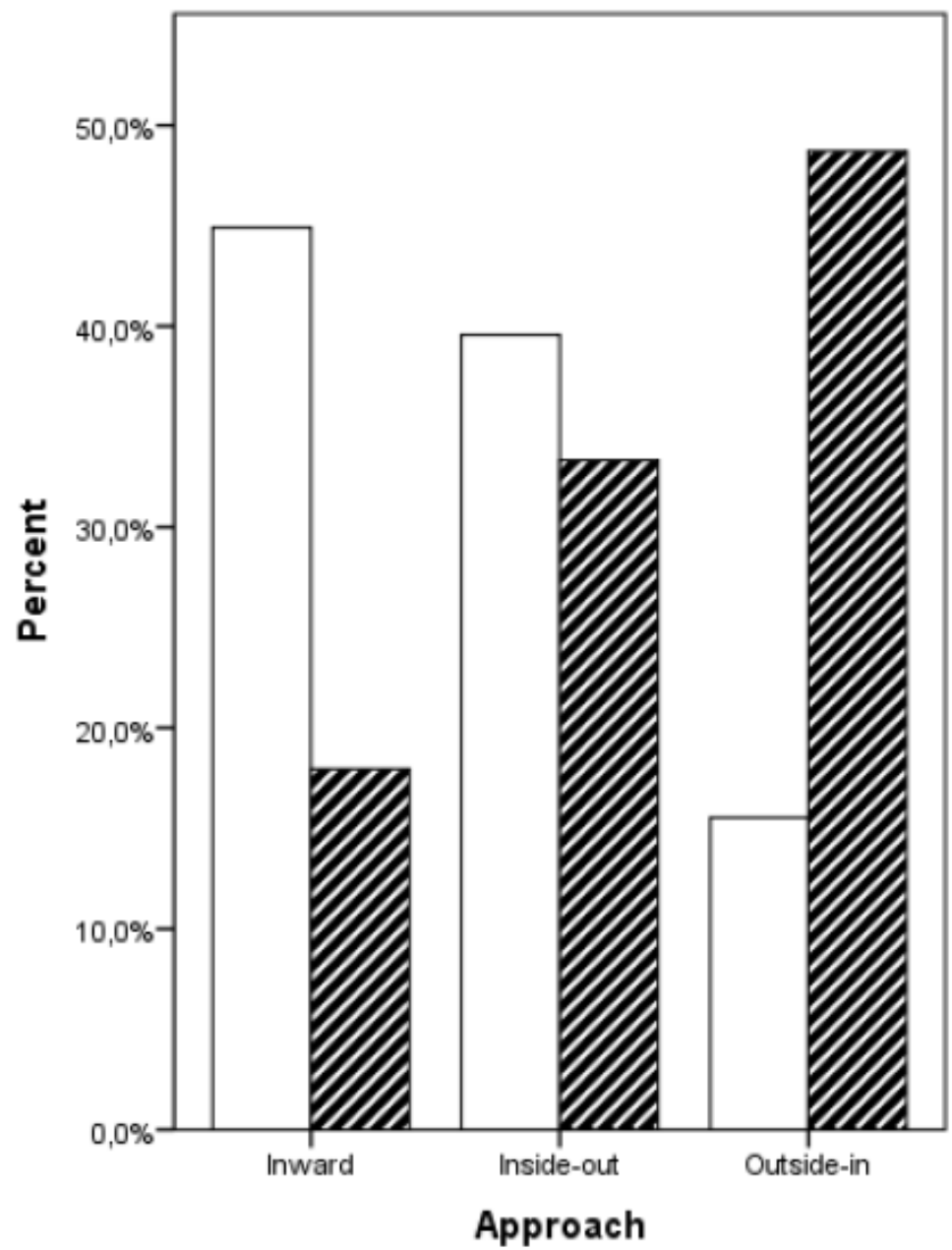

* Mixed articles are articles written by several authors, with one or more authors residing in Europe or North America and one or more authors residing in other parts of the world.

\section{Conclusion: towards an 'outside-in' research agenda}

Within EU foreign policy research, concerns about EU centrism are increasingly voiced, resulting in calls for a paradigm shift and the development of new strands of literature. Interestingly, however, what actually constitutes an 'EU-centric approach' appears to be left unaddressed, both in terms of a conceptualisation of the phenomenon and in terms of its empirical verification. This paper has therefore sought to do two things. First, building on the framework of the policy cycle, it introduced a threefold typology of approaches to the study of EU foreign policy, attempting to bring more nuance and depth to the discussion of EU-centric versus 'other' approaches and to offer a concrete tool to researchers. Second, it applied this typology to a built-for-purpose dataset of 451 articles in seven major journals, in order to map patterns of EU-centrism in post-Lisbon scholarship (2010-2014) on EU foreign policy. 
The results indicated that a very large majority of recent work on EU foreign policy focuses on the institutional underpinnings and intentions of EU external action, whereas only a very small share of articles is focused on the impact, relevance or perception of the EU's policy in a particular state or region. This is, moreover, also the case for policy fields and journals for which such an outside-in approach seems especially pertinent.

It should be stressed that this paper does not argue that individual articles have less merit because they employ an inward-oriented or inside-out perspective. Each approach has value in its own right, as it can provide key insights into EU foreign policy. What is problematic, however, is the imbalance that exists within scholarship on this topic as a whole. Periods of institutional reform such as the Maastricht and Lisbon treaties 'can explain, but [they] cannot justify, such self-centredness' (Mayer, 2008: 10). This imbalance entails that only certain research questions are habitually asked, while others are neglected. This is problematic on three levels. First, on a purely analytical level, it results in incomplete analyses and a one-sided accumulation of knowledge. Second, from a policy-oriented point of view, it leads to partial and distorted policy assessments and recommendations. This may decrease the relevance of scholarship for policy-makers. At the same time, such partial analyses may reinforce the pattern described by Cebeci, in which 'European foreign policy research feeds into the discourse of EU practitioners' and 'in turn, the new knowledge produced by EU practitioners is used by the researchers to prove and enhance their arguments' (2012: 564). Third, from a normative perspective, ignoring the point of view of the EU's counterparts is problematic, as they are major stakeholders of the EU policies and the international relations within which these are embedded.

This article argues for a diversification of the analysis of EU foreign policy, in which the existing focus on internal dynamics and EU policy implementation is increasingly complemented by outside-in perspectives and attention to impacts and outcomes. As argued earlier, this is especially pertinent for the analysis of policy areas where the EU has well-developed competences and where it primarily aims to sustainably influence structures in a third country or region. The typology presented in this paper provides a first tool for researchers interested in developing such an outside-in research agenda, as it draws attention to the wide range of core research questions that can be applied to a specific domain of EU foreign policy, including questions that are often neglected.

Assessing the outcomes and relevance of policies is a difficult task in any field, and the study of foreign policy adds to this its own challenges in terms of local knowledge, language skills and the logistics of field research. It is clear that a diversification of EU foreign policy analysis will be a challenging and long-term undertaking, one that is situated at both the level of the individual researcher and that of key knowledge producing institutions within the field. It holds potential, however, for boosting the analytical value as well as the policy relevance of academic work on EU foreign policy. 


\section{Bibliography}

Adriaensen J, Smeets N and Reykers Y. (2013) Learning to Talk the Talk: ReAppraising the External Perspective in the EU's Foreign Policy. CEU Political Science Journal 8: 296-322.

Althaus C, Bridgman P and Davis G. (2012) The Australian Policy Handbook, Sydney: Allen \& Unwin.

Bridgman P and Davis G. (2003) What Use is a Policy Cycle? Plenty, if the Aim is Clear. Australian Journal of Public Administration 62: 98-102.

Bunea A and Baumgartner FR. (2014) The state of the discipline: authorship, research designs, and citation patterns in studies of EU interest groups and lobbying. Journal of European Public Policy 21: 1412-1434.

Bürgin A. (2013) Salience, path dependency and the coalition between the European Commission and the Danish Council Presidency: Why the EU opened a visa liberalisation process with Turkey. European Integration online Papers 17: 1-19.

Cebeci M. (2012) European Foreign Policy Research Reconsidered: Constructing an 'Ideal Power Europe' through Theory? Millennium - Journal of International Studies 40: 563-583.

Chaban N and Holland M. (2008) The European Union and the Asia-Pacific. Media, public and elite perceptions of the EU. London and New York: Routledge, 239.

Chaban N and Holland M. (2014) Introduction: The Evolution of EU Perceptions: From Single Studies to Systematic Research. In: Chaban N and Holland M (eds) Communicating Europe in Times of Crisis: External Perceptions of the European Union. Basingstoke: Palgrave Macmillan, 1-23.

Cooperation and Conflict. (2014) About this Journal: Aims \& Scope. Available at: http://www.sagepub.com/journals/Journal200863/title\#tabview=aimsAndScope.

Elgström O. (2007) Outsiders' Perceptions of the European Union in International Trade Negotiations. Journal of Common Market Studies 45: 949-967.

Ergun A. (2010) Civil Society in Turkey and Local Dimensions of Europeanization. Journal of European Integration 32: 507-522.

European Security. (2014) About this journal: Aims \& scope. Available at: http://www.tandfonline.com/action/journalInformation?show=aimsScope \&journalCode=feus2 0\#.VDuR1Baumzk.

Exadaktylos T and Radaelli CM. (2009) Research Design in European Studies: The Case of Europeanization. Journal of Common Market Studies 47: 507-530.

Fisher Onar N and Nicolaïdis K. (2013) The Decentring Agenda: Europe as a post-colonial power. Cooperation and Conflict 48: 283-303.

Franchino F. (2005) The Study of EU Public Policy: Results of a Survey. European Union Politics 6: 243-252.

Givoni M, Macmillen J, Banister D, et al. (2012) From Policy Measures to Policy Packages. Transport Reviews 33: 1-20.

Hill C. (2003) The Changing Politics of Foreign Policy, Basingstoke: Palgrave Macmillan.

Hill M. (2013) The Public Policy Process, New York: Routledge.

Hill M. (2014) Studying Public Policy. An international approach. Bristol: Policy Press.

Hobson J, M. (2004) The Eastern Origins of Western Civilisation, Cambridge: Cambridge University Press.

Howard C. (2005) The Policy Cycle: A Model of Post-Machiavellian Policy Making? Australian Journal of Public Administration 64: 3-13.

Howlett M, Ramesh M and Perl A. (2009) Studying Public Policy. Policy Cycles \& Policy Subsystems, Ontario: Oxford University Press. 
Ingram HM and Fiederlein SL. (1988) Traversing Boundaries: A Public Policy Approach to the Analysis of Foreign Policy. The Western Political Quarterly 41: 725-745.

Jann W and Wegrich K. (2007) Theories of the Policy Cycle. In: Fischer F and Miller GJ (eds) Handbook of Public Policy Analysis: Theory, Politics, and Methods. Boca Raton: CRC Press, 43-62.

Jensen MD and Kristensen PM. (2013) The elephant in the room: mapping the latent communication pattern in European Union studies. Journal of European Public Policy 20: 1-20.

John P. (1998) Analysing Public Policy. Critical Political Studies. New York: Continuum.

Jørgensen KE. (2004) European Foreign Policy: Conceptualising the Domain. In: Carlsnaes W, Sjursen H and White B (eds) Contemporary European Foreign Policy. London, Thousand Oaks and New Delhi: Sage.

Jupille J. (2006) Knowing Europe: metatheory and methodology in European Union studies. In: Cini M and Bourne AK (eds) European Union Studies. Basingstoke: Palgrave Macmillan, 209-232.

Keeler JTS. (2005) Mapping EU Studies: The Evolution from Boutique to Boom Field 1960-2001. Journal of Common Market Studies 43: 551-582.

Keukeleire S. (2014) Lessons from the Practice and Analysis of EU Diplomacy from an 'Outside-in Perpective'. In: Gstöhl S and Lannon E (eds) The Neighbours of the EU's Neighbours: Diplomatic and Geopolitical Dimensions beyond the European Neighbourhood. Farnham: Ashgate, 227-241.

Keukeleire S and Delreux T. (2014) The Foreign Policy of the European Union, Basingstoke: Palgrave Macmillan.

Lentner HH. (2006) Public Policy and Foreign Policy: Divergences, Intersections, Exchange. Review of Policy Research 23: 169-180.

Lucarelli S. (2014) Seen from the Outside: The State of the Art on the External Image of the EU. Journal of European Integration 36: 1-16.

Lucarelli S and Fioramonti L. (2010) External Perceptions of the European Union as a Global Actor. Routledge/GARNET Series: Europe in the World. Oxon: Routledge.

May JV and Wildavsky AB. (1978) The Policy Cycle. London: Sage.

Mayer H. (2008) The Long Legacy of Dorian Gray: Why the European Union Needs to Redefine its Role in Global Affairs. Journal of European Integration 30: 7-25.

Mayer H and Zielonka J. (2012) Special issue 'Europe as a Global Power: View from Outside'. Perspectives: Review of International Affairs 20: 5-129.

Rayroux A. (2013) Beyond Actorness in EU Crisis Management: Internal Functions of External Peacekeeping. Journal of European Integration 35: 731-748.

Rosamond B. (2007) The Political Sciences of European Integration: Disciplinary History and EU Studies. In: Jorgensen KE, Pollack MA and Rosamond B (eds) Handbook of European Union Politics. London: Sage, 7-30.

Sabatier PA. (1992) Political Science and Public Policy: An Assessment. In: Dunn WN and Kelly RM (eds) Advances in policy studies since 1950. New Brunswick: New Brunswick Transaction.

Sabatier PA and Jenkins-Smith HC. (1993) Policy Change and Learning: An Advocacy Coalition Approach. Boulder/San Francisco/Oxford: Westview Press.

Sanchez MR, Silva ECGdS, Cardoso EL, et al. (2006) Política Externa como Político Pública: uma Análise pela Regulamentaçao Constitucional Brasileira (1967-1988). Revista de Sociologia e Política 27: 125-143.

Smith G and May D. (1980) The Artificial Debate Between Rationalist and Incrementalist Models of Decision Making. Policy \& Politics 8: 147-161. 
Ugur M. (2010) Open-Ended Membership Prospect and Commitment Credibility: Explaining the Deadlock in EU-Turkey Accession Negotiations. Journal of Common Market Studies 48: 967991.

Vedung E. (1997) Public Policy and Program Evaluation, New Brunswick: Transaction Publishers.

Versluis E, van Keulen M and Stephenson P. (2011) Analyzing the European Union Policy Process, Basingstoke: Palgrave Macmillan.

Wæver O. (1998) The Sociology of a Not So International Discipline: American and European Developments in International Relations. International Organization 52: 687-727.

\section{Notes}

${ }^{1}$ These authors contributed equally to this work.

${ }^{2}$ It will be clear by now that EU-centrism is used here in a quite specific sense, namely as a property of the research questions scholars ask and the focus they choose for their inquiries into EU foreign policy. Centrism can, however, also be defined in a more encompassing fashion. Hobson, for instance, has described Eurocentrism as 'the notion that the West properly deserves to occupy the centre stage of progressive world history, both past and present' (Hobson, 2004: 2). Such a definition of centrism is far more loaded, as it is concerned with the normative underpinnings of scholarship on international relations and foreign policy. These rather different dimensions of centrism should not be equated, nor can one be automatically inferred from the other. Therefore, when this paper describes a certain approach or research project as EU-centric, this should be interpreted only in the specific sense mentioned above.

${ }^{3}$ It has been pointed out to us that this terminology may remind some of Kenneth Waltz' three images of analysis in International Relations. As will become clear in the next paragraphs, our three categories do not correspond to these three images, nor do they serve the same purpose of explaining international outcomes. Similarly, we do not use the term outside-in in the sense put forward by Krasner, which is closely linked to Gourevitch' 'second image reversed'. Rather, we follow Mayer (and, to some extent, Nicolaïdis) concerning the meaning attached to the terms 'inside-out' and 'outside-in'.

${ }^{4}$ Another core research question that frequently recurs within the EU foreign policy literature is that of What type of international actor is the EU? or, alternatively, Is the EU a normative/civilian/ethical/market/ transformative power? Depending on the way the analysis is construed, such a research question can be combined with several of the approaches outlined above. Analyses that discuss the internal origin of the EU's international nature, without reference to the outside world, are essentially inward-looking. An inside-out analysis is obtained when scrutinizing actual EU policies towards a third country or region on the basis of such a 'power' concept, 
determining whether the EU puts it discourse into practice and is able to realise its goals. When the perspective of the partner country is taken as the point of departure for analyzing the EU's status as a particular type of power (something that is done more and more for the Normative Power Europe these), an outside-in perspective is obtained.

${ }^{5}$ Cooperation and Conflict states that 'first preference will continue to be given to articles that have a Nordic and European focus' (Cooperation and Conflict, 2014). European Security describes itself as 'a forum for discussing challenges and approaches to security within the region as well as for Europe in a global context' (European Security, 2014).

${ }^{6}$ This article opts for a focus on residence of author rather than on the highly ambiguous concept of origin of author, echoing Wæver's approach in his seminal article on the sociology of the IR discipline (1998).

${ }^{7}$ For instance, while Europeanisation studies or research questions on the effectiveness of EU foreign policy typically reflect an inside-out approach, several of these articles were nevertheless classified in other categories after evaluating the actual analysis that was undertaken. Similarly, the presence of concepts such as legitimacy and impact hints at an outside-in approach, yet this always needs to be checked against the actual operationalisation and meaning of those concepts within a specific article. For another example, see footnote 3 on Normative Power Europe.

${ }^{8}$ We are grateful to Dr Johan Adriaensen for his suggestions regarding these two dimensions.

${ }^{9}$ It should be noted that Rayroux (2013) has questioned the external objectives of CSDP missions, favoring an explanation that focuses on the internal functions of crisis management operations abroad. 